\title{
Mathematical modeling and optimization of complex structures: a review
}

\author{
Samia Riaz, Qasim Ali Chaudhry* and Sidra Siddiqui
}

*Correspondence:
alicq@kth.se
Department of Mathematics,
University of Engineering
and Technology,
Lahore 54890, Pakistan

${ }^{*}$ Correspondence:

and Technology,

Lahore 54890, Pakistan

\author{
Book details \\ Pekka Neittaanmäki, Sergey Repin and Tero Tuovinen (Eds.). \\ Mathematical Modeling and Optimization of Complex Structures; Series: Computational \\ Methods in Applied Sciences. \\ Springer International Publishing AG, Switzerland; 2016. \\ E-book, XXI, 328 pages, ISBN: 9783319235646 , Hard-cover ISBN: 9783319235639, Library \\ of Congress Control Number: 2015947948, DOI 10.1007/978-3-319-23564-6.
}

Keywords: Mathematical modeling, Complex structures, Optimization, Numerical analysis, Mechanics

\section{Overview}

Mathematical modeling and optimization of complex systems is an important area to work on. Although this domain has considerable diversity, there is only a handful of books, which specifically deal with this area. Books which focus on these topics include (Shier and Wallenius 1999; Bock et al. 2012; Melnik and Kotsireas 2012; Hömberg and Tröltzsch 2013; Hürlimann 2013; Kallrath 2013; Meerschaert 2013; Cojocaru et al. 2015; Chaudhry 2016; Hiriart-Urruty et al. 2016).

This particular text is devoted to Professor Nikolay Banichuk and was presented on his 70th birthday. He is one of the most notable scientists in various advanced fields such as solid mechanics, computational mechanics, optimal structural design, optimization and variational theory, computational algorithms and numerical methods. In this book, results demonstrated at the International Conference for Mathematical Modeling and Optimization in Mechanics (MMOM 2014) 6-7 March 2014, Finland are presented together in three main portions, i.e. numerical analysis, mathematical modeling in mechanics and optimization.

This book is really a welcome edition not only for researchers but also for graduate students to help in not only understanding various new optimization algorithms but also their application on various complex engineering problems. 


\section{Review}

In terms of organization, the book is sectioned in the following three parts.

\section{Part I}

This part is related to numerical analysis and consists of four extended papers. The first chapter is related to shape optimization of highly nonlinear coupled models. These models are used for modeling of aortic flow, based on the Koiter's shell model, where a reduced fluid structure model using Navier's stoke equations of fluid has been introduced. Model is based on transpiration and is applied on hemo-dynamics problems. The comparison study shows that this model is in good agreement with full structure models on moving mesh domains. The second paper is concerned with posteriori error estimation of functional type for non symmetric elliptic operators. This estimate has the standard properties of deviation estimate and is independent of numerical methods. The estimate is derived by using the method of integral identities and Cauchy-Schwartz-Bunyakovsky inequality. Third paper is devoted to the error estimate by using Uzawa type method for free boundary value problems. Fourth paper is on the key tool of topology optimization, the parametric level set method. To perform the shape sensitivity analysis, adjoint approach is implemented. Instead of standard approach, the state problem is differentiated in its discretized form.

\section{Part II}

Part II gathers seven papers connected with mathematical modeling of mechanics. First paper talks about harmonization of numerical, laboratory and analytical models of flows. Here, ideas of a solid figure's movement and fluid flow are set side by side by considering the state of inobservability of a fluid particle. Impacts of rubbing in sliding contact of a sphere and a visco-elastic half space are examined in the second paper. A numerical-analytical strategy is created to take care of the contact issue and to discover the contact stress distribution. Third paper concentrated on the strength of a tensioned pivotally moving plate subjected to cross-direction potential stream. Multiaxial fatigue criteria are utilized in paper 4 where an investigation of an entangled technical framework is made. Paper 5 is concerned with dynamic attributes of pivotally moving shafts with the standard linear solid sort material visco-elasticity. A projection approach in view of the strategy for integro-differential relations and semi-discretization procedure is connected to analyze natural variations of rectilinear flexible beams with non-symmetric cross areas are narrated in paper 6 . In the last paper of this section, the writers consider bifurcation sort issues emerging in the theory of elastic stability.

\section{Part III}

This part consists of six papers where the main goal of this part is to let the readers know about the optimization methods and their applications towards complex engineering problems. This part can be classified into two groups. This first group consisting of first two papers mainly deals with the algorithms of nonconvex multiobjective optimization and Nash genetic algorithms for solving inverse problems whereas the second group consisting of remaining four papers studies the dynamical modeling, control design for elastic systems and contact optimization problems. Additionally, some multipurpose optimization problems of deformed structures are also investigated. 
Price

The book can be purchased in both e-form as well as in hardcover, thereby making it easily accessible for the readers. The price is very reasonable not only for the libraries but for the individuals as well making it an economical buy. The price of eBook is \$109 whereas in hardcover, it can be purchased in $\$ 149$.

\section{Conclusions}

After reading the book, it is clear that the book covers important material, and is therefore an excellent compendium for researchers, tutors and graduate students. This is an excellent book not only for understanding new optimization algorithms but also as a tool for the implementation of new optimization techniques to complex engineering problems.

\section{Authors' contributions}

SR wrote the Part I and helped overall in writing this review. QAC wrote the Overview and Part II whereas SS wrote the Part III of this review. All authors read and approved the final manuscript.

\section{Acknowledgements}

Authors acknowledge the support provided by University of Engineering and Technology, Lahore in writing this article but they have no role in writing this paper.

\section{Competing interests}

The authors declare that they have no competing interests.

Received: 13 August 2016 Accepted: 19 August 2016

Published online: 24 August 2016

\section{References}

Bock HG et al (2012) Modeling, simulation and optimization of complex processes. Springer, Berlin

Chaudhry QA (2016) An introduction to agent-based modeling modeling natural, social, and engineered complex systems with NetLogo: a review. Complex Adapt Syst Model 4(1):1-2

Cojocaru $\mathrm{M}$ et al (2015) Interdisciplinary topics in applied mathematics, modeling and computational science. Springer, Berlin

Hiriart-Urruty J-B et al (2016) Advances in mathematical modeling, Optimization and Optimal Control. Springer, Berlin Hömberg D, Tröltzsch F (2013) System modeling and optimization: 25th IFIP TC 7 conference, CSMO 2011, Berlin, Germany, September 12-16, 2011, Revised Selected Papers. Springer, Berlin

Hürlimann T (2013) Mathematical modeling and optimization: an essay for the design of computer-based modeling tools. Springer, Berlin

Kallrath J (2013) Modeling languages in mathematical optimization. Springer, Berlin

Meerschaert MM (2013) Mathematical modeling. Academic press, USA

Melnik R, Kotsireas IS (2012) Advances in applied mathematics, modeling, and computational science. Springer, Berlin

Shier DR, Wallenius K (1999) Applied mathematical modeling: a multidisciplinary approach. CRC Press, USA

\section{Submit your manuscript to a SpringerOpen ${ }^{\circ}$ journal and benefit from:}

- Convenient online submission

- Rigorous peer review

- Immediate publication on acceptance

- Open access: articles freely available online

- High visibility within the field

- Retaining the copyright to your article

Submit your next manuscript at $>$ springeropen.com 